\title{
DEVELOPMENT OF A DIGITAL 3D PARTICIPATION PLATFORM - CASE STUDY OF WEILIMDORF (STUTTGART, GERMANY)
}

\author{
P. Würstle *, T. Santhanavanich , R. Padsala , V. Coors \\ University of Applied Sciences Stuttgart \\ Schellingstraße 24 \\ 70174 Stuttgart, Germany \\ (patrick.wuerstle, thunyathep.santhanavanich, rushikesh.padsala, volker.coors) @ hft-stuttgart.de
}

KEY WORDS: Public Participation Platform, 3D City Models, CityGML, 3D Web Visualization, Open Geospatial Consortium

\begin{abstract}
:
This paper explains the development of a 3D city model-based Public Participation Platform as a prototype and its implementation in a real-world public participation process to redevelop the Weilimdorf area of Stuttgart city. Alongside conducting Weilimdorf's public participation process, the goal of the mentioned public participation platform is to research citizens' acceptance of such tools. The usage of digital tools has become more critical for participation processes. The need for social distancing expedites this change, particularly during the pandemic. Previous research frequently focuses on 2D platforms and smaller sample sizes but nevertheless shows the importance of such tools. However, with current developments in geospatial and web streaming technologies, it has become easier and faster to visualize large-scale 3D city models over the web. In this research, these technologies were used by the citizens of the Weilimdorf area to evaluate the usability of the platform and collect their feedback. The result shows that such a digital public participation platform is a valuable supplement to traditional in-person public participation methods.
\end{abstract}

\section{INTRODUCTION}

Our world is urbanizing at an exceptional rate than ever before. By 2050, a study from the United Nations predicts that $68 \%$ of the world population will be living in urban areas compared to $53 \%$ in 2014 (UN, 2014). This itself gives an idea about the extra infrastructural load and demands citizens will ask from their governments. Today, in the time where every city aims to become a "Smart City", it is very critical for local governments to understand that while delivering "wow", they do not lose the vision on what citizen needs "now". Hence an essential stakeholder for solving such a challenge are the citizens themselves by making them involved in the decision-making process. (Marzouki et al., 2017) defined the citizen participation process as a way in which citizens can effectively share their life circumstances by communicating their problems and demands to the government for their neighborhood, city, and country. Such communications help in the decision-making process and help strengthen the democracy and confidence of citizens in government by providing the platform and opportunities to get involved in making a more intelligent, better world of tomorrow. A result that is valuable for citizens, city planners, and the government made with the consent of the public will be more widely accepted by everyone and helps in validating both top-down and bottom-up approaches in governance.

Traditional public participation methods, like survey questionnaires, public meetings, are generally no more favored by the citizens. Such methods do help in knowing citizens' mindsets, but makes it tough for citizens to understand the complex interdependency of multiple city development indicators due to minimal use of city visualization methods. Additionally, such participation methods are usually held during working days at a fixed place and time when people are often at work or in the evening where other commitments either restrict them to

\footnotetext{
* Corresponding author.
}

fully participate in the public meetings or prevent them from attending them (Kingston, 2007). This is now backed by the COVID-19 pandemic, which changed the traditional working culture globally. Citizens are instructed by their government to work from home and only leave their houses in times of desperate need. Information and communication technology (ICT) presents a realistic alternative, especially when face-toface meetings are taken over by online meeting applications and mobile technologies with $4 \mathrm{G} / 5 \mathrm{G}$ services transforming how users use the internet for communication and interaction with others. Such innovation has also led different countries' political systems to adapt and become more responsive, transparent, and oriented towards public-oriented policies for better governance and a sustainable urban environment. This led to coining a new terminology, e-participation, which, together with edemocracy, forms e-Government.

This paper presents a first insight into the 3D city model-based prototype of a digital public participation platform currently under development at the University of Applied Sciences, Stuttgart. As its first real-world use case, the prototype is tested on around 500 Weilimdorf's citizens to collect their views and ideas on further redevelopment of their neighborhood by a local city developer, STEG, in collaboration with the municipality of Stuttgart. The participants came from the entire Weilimdorf district. This paper aims to explain the prototype's technical development process and the feedback received on the user interface (UI), user experience (UX), and what, according to citizens, are essential components for a digital public participation platform.

\section{RELATED WORK}

With innovations in ICT tools, using an e-participatory platform for citizen participation in urban planning is not new. Moreover, traditional planning methods have been immensely transformed using innovative ICT tools and techniques (Knapp and Coors, 
2007), (Silva, 2010), and (Yigitcanlar and Velibeyoglu, 2008). Over the last decades, web-based technologies, especially webbased geo-visualization tools, have been widely used and accepted to cater to citizen participation. Much research literature has also validated the impact of using 2D web maps and applications to initiate cities' public participation process (Ganapati, 2010), (Rall et al., 2019), (Narooie, 2014), and (Hansson et al., 2017). Even though 2D maps are good at sharing and visualizing information, they still miss that cutting edge to understand reality and visualize complex urban issues most effectively. Increasing development in 3D geo-visualization over past years has allowed users to share and visualize geo-referenced 3D models of entire cities on the web. Over 2D maps, the rapid development of web-based 3D geo-visualization tools has benefited the development of interactive 3D applications for the e-Participation platforms and has provided many advantages concerning communication, cooperation, and particularly participation (Knapp and Coors, 2007). Mutually, there has been understanding and agreements between scholars that 3D geovisualization can effectively improve the understanding and visualization of the current scenario and problem statement. Previously, these web-based 3D visualization tools were based on virtual globes like Google Earth which revolutionized 3D visualization worldwide. However, three significant issues emerged 1) a lack of high-resolution $3 D$ content, 2) users' necessity to download a plugin for use in a web browser and 3) performance on the web.

Specifically, for Google Earth, with Trimble acquiring Google Sketch-up with its 3D warehouse, it was no longer possible that users could directly upload their 3D models on Google Earth. As an alternative, Cesium, a web globe built on JavaScript API, allowed users to have complete control of their web application. Furthermore, in previous research by (Würstle et al., 2019) Cesium 1 was compared to other web globes such as NASA Web World Wind ${ }^{2}$ and Google Earth ${ }^{3}$ Cesium uses WebGL to render 3D and without any need for an extra browser plugin. Cesium is capable of delivering web-based 3D geovisualization anytime, anywhere. Closest to the Cesium Web Globe in terms of functionalities and support of different 3D data formats are Esri's web globe, which can be controlled by the ArcGIS API for JavaScrip ${ }^{4}$ and the Mapbox webmap platform ${ }^{5}$, which the Mapbox GL JS can control. Mapbox GL JS is a JavaScript library used for rendering interactive 2D and 3D maps. Cesium supports a variety of vector formats like KML, GeoJSON, TopoJSON, glTF, and its own content delivery format of 3D Tiles, which supports CityGML. CityGML is an open data model and XML-based data format from Open Geospatial Consortium to store and exchange virtual 3D city models (Gröger and Plümer, 2012). Today more than 100 cities worldwide have their 3D city models in CityGML models available free for the public uses (Delft University of Technology, 2019). Additionally, similar to other web globes, Cesium allows integrating static/dynamic vector data, multiple web services, terrain profiles, and satellite imagery into a single virtual environment, making public participation much more intuitive and exploratory. virtualcitysystems $\mathrm{GmbH}(\mathrm{VCS}){ }^{6}$ has developed a web-based client, VC Map on top of Cesium, administered by the VC Publisher.

\footnotetext{
$1 \longdiv { \text { https://cesium.com/ } }$

2 https://worldwind.arc.nasa.gov/web/

3 https://www.google.com/earth/

4 https://developers.arcgis.com/javascript/latest/

5 https://wWw.mapbox.com/

6 https://vc.systems/en
}

Although 3D geo-visualisation has been applied in citizen participatory processes before, and a list of functionalities that a citizen participation platform should incorporate is well available (Steiniger et al., 2016), there is still a lack of use cases in using web 3D geo-visualisation to cater to the citizen participation process. Many public participatory applications use 2D web maps and only small modules or test cases in 3D - primary reasons being time and skills required to program a 3D participatory platform. This comes as a surprise considering the amount of open data initiatives take from the governments, use cases demonstrated where 3D geo-visualization is successfully used, current advancement and available technologies that can be used for building dynamic web-based 3D applications than before. A quick review of the literature shows further development and use cases of the participatory platform and shows how 3D GIS can play an essential role in public participatory platforms. (Steiniger et al., 2016) and (Goetz, 2008), in their literature, pointed out the functionalities an e-planning platform should have.

Additionally, they also emphasized user-centered design, which included 3D GIS as a critical module. Beaudreau in YouSayCity (Beaudreau, 2011), a 3D online public participation platform, demonstrated the integration of 3D city models in KML using Google Earth API. This development's important outcome included 3D-oriented discussion forums, visualizing 3D KML models on the web, and interactive surveys on a web platform. Hu et al. (Hu et al., 2013) demonstrated another such participation platform wherein a standalone application was deployed on each client machine with synchronization to server machine where all the project-related data were hosted. Client machine hosted 3D viewer based on Skyline glove viewer, a group of simple analytical functions, a set of collaboration tools, and a communication module. Taking a step forward, Khan et al. (Khan et al., 2014), under the UrbanAPI project, demonstrated that different kinds of ICT applications for urban planning could be developed and applied at different urban scales for collaborative decision-making and policy development. Two essential applications demonstrated here were the introduction of Virtual Reality developed for the general public (bottomup approach) due to its higher visualization appeal based on X3DOM and Urban Growth Simulation based on agent-based models (ABMs) for land-use change simulation. Based on the Urban API finding, Khan et al. (Khan et al., 2017) again developed a citizen participation platform to support smart city decision-making coined as Smarticipate. Smarticipate platform is based on a micro-services-based approach that allows the development of individual features as a web service with less dependency on each other. It uses domain-specific language to analyze citizen proposals and generates automated feedback based on open government data. Also, in a similar category is the open-source DIPAS platform. DIPAS platform is a joint project of the Authority for Urban Development and Housing with the State Office of GeoInformation and Surveying and the CityScienceLab of HafenCity University in Hamburg, Germany. With DIPAS (Lieven, 2017), along with existing development, future developments can also be visualized both in 2D and 3D. Additional elements such as automated report generation, integration with open geodata of Hamburg and functionality to visualize future masterplans using Xplanung data standards makes DIPAS one of a kind public participation platform.

One future goal of the platform prototype presented in this paper is to take a step forward by integrating an urban simulation engine SimStadt. Having a connection to SimStadt in the back- 
end will allow both citizens and decision-makers to simulate and visualize what-if scenarios for an even better and informed decision making in particular for the building stock energy demand and renewable energy potential present on site. However, it being a future vision, the present paper focuses more on the prototype's technical development in its current state and documents citizens' feedback on its overall UI and UX.

\section{IMPLEMENTATION}

\subsection{Application}

The participation project is based around an area in Weilimdorf. Weilimdorf is a district in Stuttgart. The area belonged to a former gardening company and has been bought by the city. It is of great importance for the residents, based on its position, use, and size. It is planned to create a development concept that provides the framework for all future developments (Noller, 2021). The application focuses on the four areas that are of interest for the new development. Area A includes a youth cen-

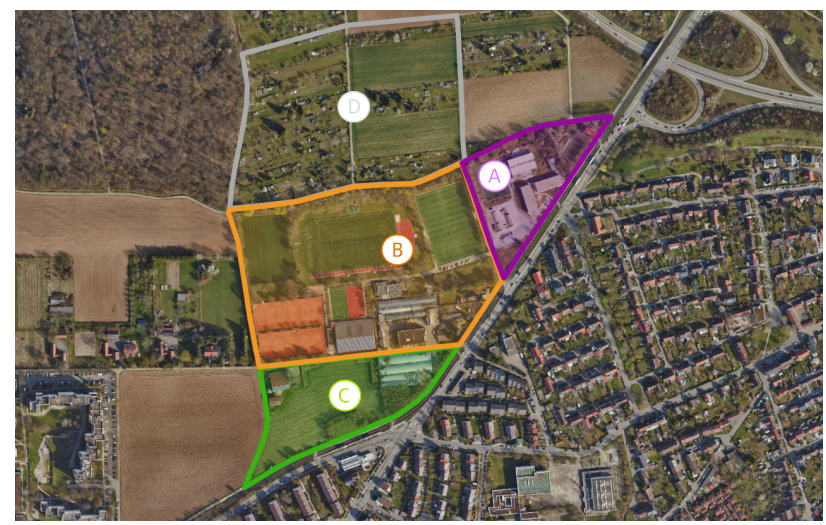

Figure 1. Area Weilimdorf (Imagery provided by the city of Stuttgart)

ter, a daycare, and a refugee shelter. Because there are already these facilities in this area and it has a central location and good connection to public transport a community center is planned here. Area B is already hosting different sports clubs. Area C contains the former gardening company and some free spaces. These should be kept free of buildings to keep their significance for the urban climate.

The platform shows the map with buildings and terrain. The blue markers visible in figure 1 show the location of the points of interest in the area. By clicking on them, a context window opens up on the right side of the application. This is also where the survey is opened. The Questionnaire in figure 3 was set up in two parts. The first being the specific questions regarding the participation process. The STEG has devised the questions for the first part. The second part of the questions gives the participants the chance to evaluate the platform (Section 4) and give feedback on the process. The functionality of the platform was capped at this point to keep the entry-level for participants low. It is possible to let users create their own designs with 3D models with the tools available. Previous studies (Würstle et al., 2019) have shown that this is difficult for people who are less adept with these kinds of tools and require an extensive introduction in the process.

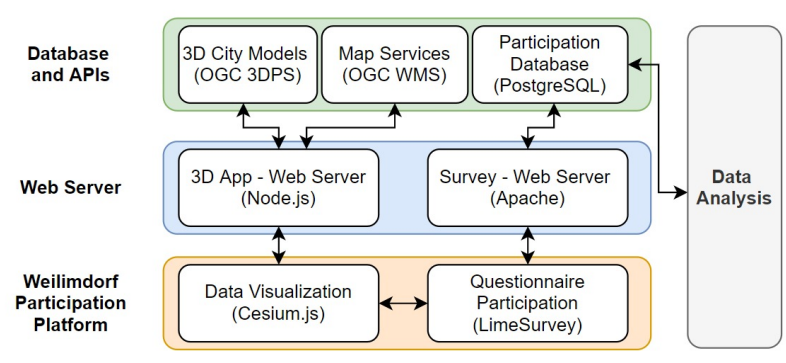

Figure 2. System Architecture

\subsection{System Architecture}

3.2.1 Database and APIs The main data that is used for visualization purposes comes from the city and the STEG. The city provides a CityGML dataset of the buildings in the region in LoD2 and an OGC Web Map Service (WMS) for the background map. The CityGML model was converted to the 3D Tiles OGC Standard for visualization using the Feature Manipulation Engine (FME) ${ }^{7}$ data integration platform from Safe software. Additionally, a terrain set was provided to visualize the surrounding area and give a better impression of it. The terrain was converted from GeoTIFF to the quantized mesh format in a similar fashion. The data conversion pipeline from GeoTIFF to the streaming formats is also developed using the FME software. Contrary to the terrain and the building model, which were only provided for the purpose of this project, the WMS is publicly available for non commercial use. It shows the areal photos from 2015 of the region and is provided over the ArcGIS service of the city. It has a ground resolution of $20 \mathrm{~cm}$ at the highest scale of 1:500.

These datasets build the basis for the visualization of the surrounding environment. The content data for the region was provided by the STEG and, in extension, the clubs and other stakeholders in the area. The data includes pictures and text introducing the area, the stakeholders, and certain specific interest points. For a better understanding of the region, a geojson dataset was created that describes the specific areas of interest.

The HFT Stuttgart acquired additional data in the project describing the social structure in the area from Infas 360 . This gives the possibility to draw conclusions on the participation rate among the citizens living in the area.

3.2.2 Web Server Two open-source servers were in use for the purpose of hosting the Cesium application and the survey tool. Node. $\mathrm{j}^{8}$ is an asynchronous JavaScript runtime used to host the Cesium application. It utilizes the Express framework. In addition, an Apache HTTP Server is used to host the Limesurvey $\sqrt{9}$ online survey tool. A Virtual Ubuntu 18.04 Machine is used to run both of the Web servers.

3.2.3 Data Visualization The visualization's basic framework is built on the Cesium WebGL library, which supports several geospatial data formats such as gITF and GeoJSON. Cesium's 3D Tiles format is a data format for optimized 3D data streaming through the web. It is used for the visualization of 3D Buildings. Cesium can visualize different terrain formats, such as quantized-mesh, GeoTIFF, Floating Point Raster, USGS ASCII DEM and CDED.

\footnotetext{
7 https://www.safe.com/

8 https://nodejs.org/en/

9 https://www.limesurvey.org/
} 


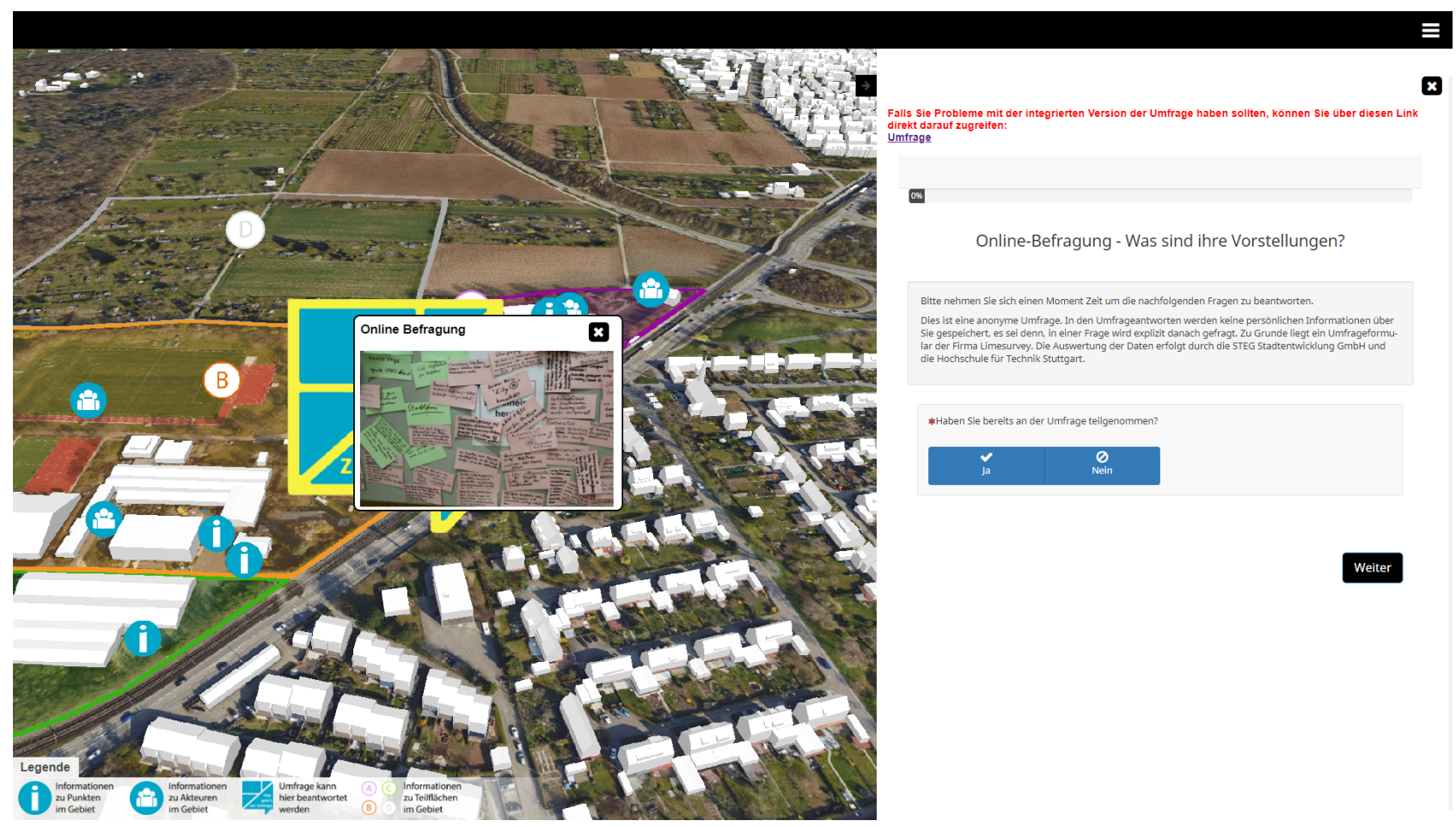

Figure 3. Layout Questionnaire

To deliver the 3D Tiles dataset in a standardized way, an API server was implemented, followed by the OGC 3D Portrayal Service ${ }^{10}$ (3DPS) as our 3D geospatial content delivery implementation specification. With the 3DPS, 3D contents can be retrieved as an HTTP/GET Key-Value Pair (KVP)-based request as shown in the listing 1 It is an example request with important KVP encodings used to request the specified 3D contents on our visualization platform.

\section{Listing 1. Example 3D Portrayal Service URL}

http://[IP Address] : [Port]/service/v1?

service $=3$ DPS

\&acceptversions $=1.0$

\&request $=$ GetScene

\&boundingbox $=9.40,49.05,9.51,49.10$

\&lods $=2$

\&layer=building

\&format=application/json+3dtiles

Moreover, we also integrated the Web Map Service layer as our basemap in the 3D web application.

3.2.4 Questionnaire To conduct the survey for the participation process, the open-source tool Limesurvey was used. Limesurvey provides two options for using the software. One is to acquire a server instance from Limesurvey, the other to host the software by oneself. The self-hosting solution was used in this project. Limesurvey is built with PHP and Javascript. It uses TWIG to allow the creation of Templates that can be seen on the frontend. Limesurvey also provides a backend to evaluate the survey and give a first visual impression of the participation. To install the software on a server, a database, in this case, Postgres 9, and PHP libraries are required.

\footnotetext{
10 http://docs .opengeospatial.org/is/15-001r4/15-001r4. html\#_getscene_request
}

Limesurvey provides different possibilities of setting a survey up. Access to the questionnaire can be restricted over Tokens or an IP or kept open. No validation method was selected to not limit the participants and have a barrier of entry that is as small as possible. This also allowed for maximum anonymity.

\section{USER EVALUATION OF THE PLATFORM}

In some previous studies by (Lafrance et al., 2019) or (Mahmoud and Takafumi, 2011), the focus is on qualitative feedback with a small number of participants. In this research, around 500 citizens have taken part in the participation process. The participation and the questionnaire were anonymous and no data on the participants was saved only their answers. The Results of the first part that regard the project and the area were evaluated by the STEG and will be presented to the city. In this part the citizens were asked to comment on certain aspects of the Area and what future developments they would like to see. The second part that relates to the platform and the digital process itself is evaluated in the following paragraphs. 480 of the participants that started the survey answered the second part.

\subsection{Participants}

The gender distribution of the participants is balanced with $45 \%$ female, $44,8 \%$ male, and $0,6 \%$ divers $(9,6 \%$ did not answer). This corresponds to the data on the area with $50,65 \%$ female and $49.35 \%$ male.

The age of the participants follows a normal distribution. Based on the survey responses, $8.75 \%$ of the participants are over the age of 65 . In the region, around $18.89 \%$ of the inhabitants fall in the age range of 65 and over. The participants below the age of 20 make up $7.92 \%$ of the overall participants. The data of the region only shows the inhabitants with an age of 18 and below. This does not match the age ranges of the survey but still gives 


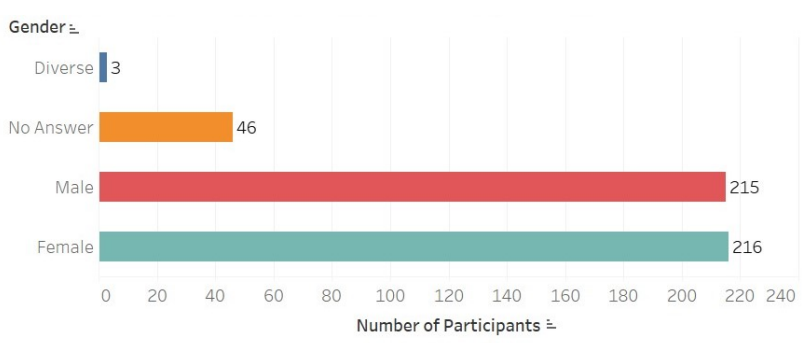

Figure 4. Gender distribution

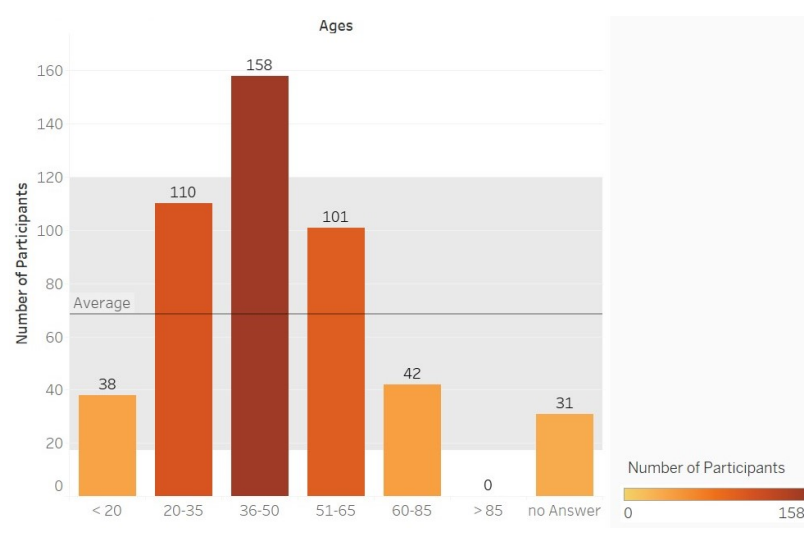

Figure 5. Age distribution

a general idea of the composition in the area compared to the survey participants. The citizens below the age of 18 make up $20.7 \%$ of the inhabitants in that region. Participants in the age range between 20 and 65 make up $76.88 \%$ of all participants. The inhabitants in the age range between 18 and 65 make up $60.42 \%$ of all inhabitants. This indicates that disproportionately more people in the age range of 20 to 65 partook in the participation process based on the region's inhabitants. However, it doesn't factor in participants who are not living in the area $(23.34 \%)$ and the people who didn't give any information on their age $(6.46 \%)$.

\subsection{Evaluation Question}

The participants were given six questions to evaluate and rate their experience with the platform. The first question asked the participants how content they were in general with the use of the $3 \mathrm{D}$ platform. The participants were given four options, very dissatisfied $(7.27 \%)$, somewhat dissatisfied $(16.96 \%)$, rather satisfied $(39.65 \%)$, and very satisfied (19.82\%). $16.3 \%$ did not answer the question. This indicates that generally, the users were satisfied. The following questions provided a statement to the participants and asked them if they agree on a scale of 1 (do not agree at all) to 5 (agree completely).

The participants' answers to the statements shown in table 1 mostly agree with the statements. Only the ease of use is below a rating of four. This shows that the participants are in favor of digital complements to ordinary participation processes. The Fourth Statement in the table focuses on the aspect of having a map to answer the questions compared to not having one.

A concern was raised in the written feedback part that older participants were excluded from digital participation processes because of lacking digital competence. The data on the age ranges suggest that fewer people on both ends of the spectrum have taken part, and most are between 20 and 65 . The answers

\begin{tabular}{|l|l|l|}
\hline statement & $\mu$ & $\sigma$ \\
\hline \hline (1) "I find the platform useful" & 4.14 & 1.0 \\
\hline (2) "I find the platform easy to use" & 3.93 & 1.21 \\
\hline $\begin{array}{l}\text { (3) "I find the use of digital media in cit- } \\
\text { izen participation processes helpful" }\end{array}$ & 4.52 & 0.86 \\
\hline $\begin{array}{l}\text { (4) "The 3D platform helps me better un- } \\
\text { derstand information spatially in the plan } \\
\text { area" }\end{array}$ & 4.01 & 1.09 \\
\hline $\begin{array}{l}\text { (5) "I find the 3D platform an innovative } \\
\text { form of citizen participation" }\end{array}$ & 4.28 & 1.00 \\
\hline
\end{tabular}

Table 1. Evaluation of the statements

of participants in the 65 and above age group for the statement questions are overall in line with the overall numbers. However, the answers are consistently a few points lower than the average. Nevertheless, the participants mostly agree on all statements. This suggests that people above the age of 65 are not necessarily hindered by an online participation tool.

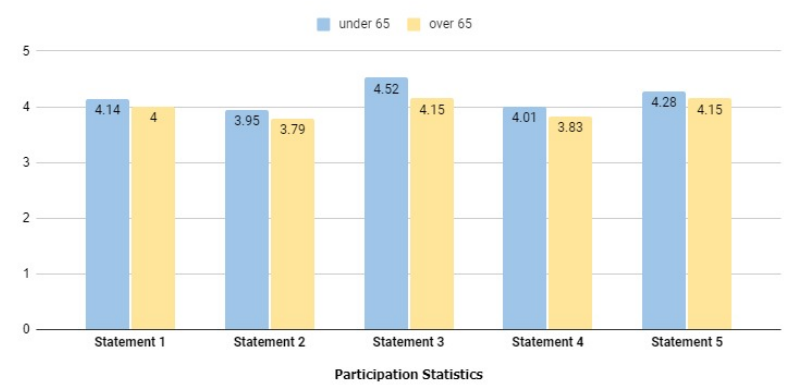

Figure 6. Comparison between age groups

The number of participants in the age range of 20 to 65 compared to the inhabitants suggests that comparatively more people in this age range participated. Based on the project partner STEG's experiences, offline participation processes often tend to an older demographic. This further indicates that online participation and the on-demand availability of it help citizens with obligations that would usually prohibit them from participating in taking part. The evaluation of the written feedback gives an overview of some areas that would benefit from improvement. The feedback can mainly be categorized into four major groups.

- Additional Functionality (20 participants)

- Technical Improvements (38 participants)

- Visual Improvements (16 participants)

- Content Improvements (13 participants)

These written suggestions give an excellent starting point to continue and further develop the platform. The feedback on the additional functionalities requested by the participants is often already included in the platform, suggesting that they were not presented in a way that allows the participants to find them intuitively. Two participants also directly ask for better explanations of the functions. The demand to be able to rotate the area, 
for example, is an integral function of the Cesium web globe. The request to be able to see the 3D map during the answering of the questionnaire (8 participants) is also already possible on the desktop version of the website but not on the mobile version. This shows that it is essential to think about adding this functionality also to the mobile version. A good mobile version appears to be important because ten participants also requested improvements on the mobile version directly. These have been categorized as technical improvements.

\section{CONCLUSION AND OUTLOOK}

The results of the user feedback show that online participation is a viable option to enhance offline processes. The statement describing the digital media use in participation processes has the highest number of agree with the lowest standard deviation. This leads to the conclusion that digital tools should be part of participation processes. The statement regarding the ease of use has the lowest rating, but still, favors agree. The higher standard deviation indicates that the divide between participants is the highest here. This can be the result of different levels of familiarity with technologies such as Google Maps.

Furthermore, the results show that digital participation's target audience differs from on-site participation based on experience. The demographic for digital participation is mainly found in participants from 20 to 65 years. This can be traced back to the fact that online participation is not set to specific times of the day and does not require a considerable time commitment to allow people to participate with long work hours or otherwise less flexible schedules. Sadly because no in-person event was possible, participation could not be compared between the two processes. Therefore no clear statement can be made if the inperson participation process would have seen the same, more or less participation.

To further develop the participation platform in a next step, an eye-tracking study will be set up. For this purpose, a small group of citizens and experts in the field will be invited to join. The setup will consist of a screen and a camera tracking the eye movements of the participant. This should result in precise feedback on the User Interface of the platform. The platform will also be used in another Project in the Nordbahnhof area of Stuttgart.

\section{ACKNOWLEDGEMENTS}

The authors would like to thank the Geoinformatics Department of the State Office for Spatial Information and Land Development (LGL) Baden Württemberg for their fruitful longterm collaboration. Additionally, the authors want to thank the STEG for the collaboration on this project and virtualcitysystems GmbH for providing Software components to the HFT. The project on which this article is based was funded by the Federal Ministry of Education and Research under the number 03IHS032A. The responsibility for the content of this publication remains with the author

\section{REFERENCES}

Beaudreau, P., 2011. Yousaycity: an online 3d public participation tool for urban planning, master thesis, mcgill university.

Delft University of Technology, 2019. Cities/regions around the world with open datasets. https://3d.bk.tudelft.nl/opendata/opencities/.
Ganapati, S., 2010. Using geographic information systems to increase citizen engagement.

Goetz, N., 2008. Buergerbeteiligung 2.0, masters thesis, university of applied sciences stuttgart.

Gröger, G., Plümer, L., 2012. CityGML - Interoperable semantic 3D city models. ISPRS Journal of Photogrammetry and Remote Sensing, 71, 12-33. https://doi.org/10.1016/j.isprsjprs.2012.04.004.

Hansson, K., Ekenberg, L., Cars, G., Danielson, M., 2017. An e-participatory map over process methods in urban planning. 13th International Conference for E-Democracy and Open Government.

Hu, Y., Lv, Z., Wu, J., Janowicz, K., Zhao, X.and Yu, B., 2013. A Multi-Stage Collaborative 3D GIS to Support Public Participation. International Journal of Digital Earth, 8, 212-234.

Khan, Z., Dambruch, J., Peters-Anders, J., Sackl, A., Strasser, A., Fröhlich, P., Templer, S., Soomro, K., 2017. Developing knowledge-based citizen participation platform to support smart city decision making: The smarticipate case study. Information (Switzerland), 8, 47.

Khan, Z., Ludlow, D., Loibl, W., Soomro, K., 2014. ICT enabled participatory urban planning and policy development. Transforming Government: People, Process and Policy, 8, 205229.

Kingston, R., 2007. Public Participation in Local Policy Decision-Making: The Role of Web-Based Mapping. The Cartographic Journal, 44, 138-144.

Knapp, S., Coors, V., 2007. The use of eParticipation systems in public participation: The VEPs example. Urban and Regional Data Management - UDMS Annual, 93-104.

Lafrance, F., Daniel, S., Dragićević, S., 2019. Multidimensional Web GIS Approach for Citizen Participation on Urban Evolution. ISPRS International Journal of Geo-Information, 8(6). https://www.mdpi.com/2220-9964/8/6/253.

Lieven, C., 2017. DIPAS - Towards an integrated GIS-based system for civic participation. Procedia Computer Science, 112, 2473-2485.

Mahmoud, H., Takafumi, A., 2011. A Web-Based Public Participation System that Supports Decision Making. Journal of Asian Architecture and Building Engineering, 10(2), 77-84.

Marzouki, A., Lafrance, F., Danie, S., Mellouli, S., 2017. The Relevance of Geovisualization in Citizen Participation Processes. 397-406.

Narooie, M., 2014. Boosting public participation in urban planning through the use of web gis technology: A case study of stockholm county.

Noller, T., 2021. Entwicklung des walz-areals. https://www.stuttgart-meine-stadt.de/stadtentwicklung/walzareal/.

Rall, E., Hansen, R., Pauleit, S., 2019. The added value of public participation GIS (PPGIS) for urban green infrastructure planning. Urban Forestry and Urban Greening, 40, 264-274.

Silva, C., 2010. Handbook of research on e-planning: Icts for urban development and monitoring. 
Steiniger, S., Poorazizi, M. E., Hunter, A. J. S., 2016. Planning with Citizens: Implementation of an e-Planning Platform and Analysis of Research Needs. Urban Planning, 1.

UN, 2014. World Urbanization Prospects: The 2014 Revision. $1-4$.

Würstle, P., Santhanavanich, T., Coors, V., 2019. The development of an e-participation platform for rural areas in the study area of niedernhall. REAL CORP 2019: IS THIS THE REAL WORLD?, 731-737.

Yigitcanlar, T., Velibeyoglu, K.and Baum, S., 2008. Handbook of research on e-planning: Icts for urban development and monitoring.

\section{APPENDIX}

\subsection{Privacy Policy}

\section{Original Version:}

Bitte nehmen Sie sich einen Moment Zeit um die nachfolgenden Fragen zu beantworten.

Dies ist eine anonyme Umfrage. In den Umfrageantworten werden keine persönlichen Informationen über Sie gespeichert, es sei denn, in einer Frage wird explizit danach gefragt. Zu Grunde liegt ein Umfrageformular der Firma Limesurvey. Die Auswertung der Daten erfolgt durch die STEG Stadtentwicklung $\mathrm{GmbH}$ und die Hochschule für Technik Stuttgart.

Translated Version:

Please take a moment to answer the questions below.

This is an anonymous survey. No personal information about you will be stored in the survey responses unless a question explicitly asks for it. The survey is based on a survey form from the company Limesurvey. The data is analyzed by STEG Stadtentwicklung GmbH and the Stuttgart University of Applied Sciences. 